Fac. of Vet. Med., Beni-Suef, University.

\title{
PREVALENCE AND PATHOGENISITY OF CAMPYLOBACTER SPECIES IN CHICKENS IN EL FAYOUM GOVERNORATE
}

(With 4 Tables)

By

\author{
F.R. EL-SEEDY; I.A. RADWAN; \\ MERVAT M. ABDALLA* and NAGLA F.O. TOLBA* \\ * Fayoum Provincial Laboratory, Animal Health Research Institute.
}

(Received at 17/9/2008)

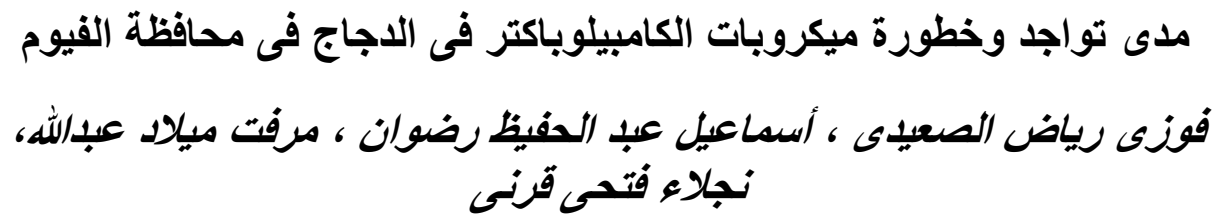

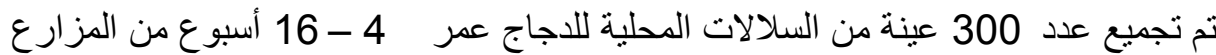

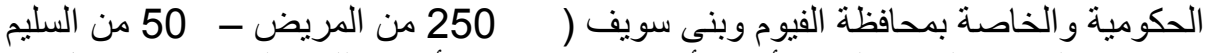

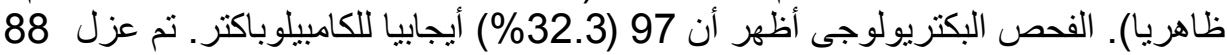

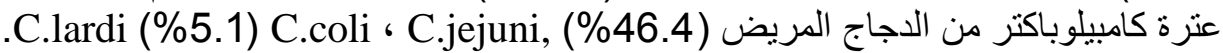

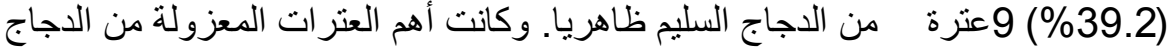

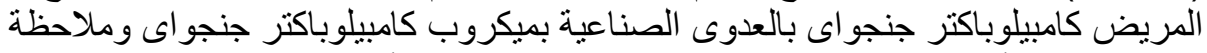

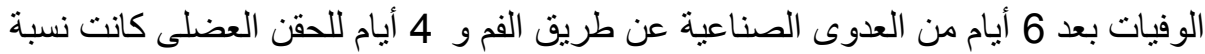

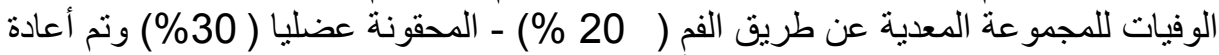

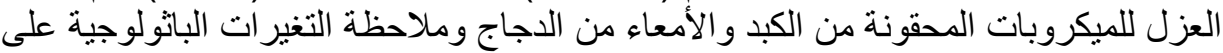
هذه الأعضاء. - الميكروبات

\section{SUMMARY}

A total of 300 (250 clinically diseased and 50 apparent healthy) local breeds chickens (4 to 16 weeks old) were collected from different governmental and private farms at El-Fayoum and Beni Suef Governorates were employed. Bacteriological examination showed that $97(32.3 \%)$ were positive for Campylobacter species. Those cases consisted of 88 isolates were recovered from 250 clinically diseased chickens and 9 isolates from 50 apparent healthy ones. Out of the examined 88 isolates of Campylobacter recovered from the diseased chickens, 45 were $C$. jejuni, 38 were $\mathrm{C}$. coli and 5 were $C$. lardi with an 
incidence of $46.4 \%, 39.2 \%$ and $5.1 \%$ respectively. From apparent healthy chickens the 9 recovered isolates consisted of $6 C$. jejuni and 3 $C$. coli. The recovery rate from different sites of all the examined chickens was almost equal from the Jejunum (44.3\%) and caecum $(43.3 \%)$, while it was in a descending rate from the liver $(9.3 \%)$, gall bladder $(2.1 \%)$ and heart blood $(1.0 \%)$ as the number of Campylobacter species that were isolated from the jejunum, caecum, liver, gall bladder and heart blood was 43, 42, 9, 2, and one respectively. From diseased chickens, Campylobacter jejuni was mainly isolated from jejunum (29 isolates), followed by caecum (12 isolates), liver (3 isolates) and once from gall bladder contents. Campylobacter coli was mainly recovered from caecum ( 26 isolates), followed by jejunum ( 8 isolates), liver tissues (2 times), gall bladder and heart blood (1 isolate each). Campylobacter lari was recovered from jejunum ( 2 isolates) and liver tissues (3 isolates). In apparent healthy chickens, Campylobacter jejuni was isolated from jejunum (3 isolates), followed by caecum ( 2 isolates) and liver tissues (1 isolate), while Campylobacter coli was recovered from caecum ( 2 isolates) followed by jejunum (1 isolate). Experimental infection with Campylobacter jejuni showed that the first mortalities was recorded 6 days post infection in orally infected group and 4 days in intramuscularly infected group of chickens. Mortality rate was $20.0 \%$ $(4 / 20)$ in orally inoculated group and $30 \%(6 / 20)$ in I.M. infected group. Re-isolation of the inoculated microorganism was recorded from the liver, caecum and jejunum from 3 (out of the 4 dead) orally infected chickens, and from. 5 (out of the 6 dead) I.M. inoculated ones. Rectal swabs that were collected from living chickens at the end of the experiment showed that $C$. jejuni was recovered from 3 living chickens of orally infected group and 2 from I.M. injected group. Experimental infection with $C$. coli produced $25.0 \%$ and $20.0 \%$ mortalities when inoculated I.M and orally respectively. The principal changes were in the form of distension of the intestinal tract. Intramuscular inoculation of C. jejuni and $C$. coli in a mixed form produced $35.0 \%$ mortality rate with severely detectable pathological changes in the liver, accumulation of mucus and watery fluid in duodenal loop and hemorrhages in the intestinal tract. The mortality rate lowered to be $25.0 \%$ accompanied with severe dehydration and blood tinged duodenal mucosa when the two organisms were inoculated orally.

Key words: Chickens, Campylobacter species, C.jejuni, C.coli. 


\section{INTRODUCTION}

Campylobacteriosis, caused by Campylobacter species, is an important food-borne disease of specific concern to consumers of undercooked poultry meat (Simon, 1992). The contamination of poultry meat usually occurs after slaughtering when the organisms spread from the intestinal contents of the affected birds to the carcasses during the process of evisceration (Simmons and Gibbs., 1979). In chicken farms, the main transmission route of this microorganism is horizontal, as the vertical route continues to be the object of inconclusive researches (Fonseca et al., 2006).

Campylobacter microorganisms are Gram-negative, spiral and/or curved non-spore forming, $0.2-0.9 \mu \mathrm{m}$ wide and 0.5-5 $\mu \mathrm{m}$ long. They are oxidase positive with at least one polar flagellum at one or both end, giving a corkscrew or darting motility (Bolton et al., 1992).

In poultry, Campylobacter jejuni is responsible for avian vibrionic hepatitis, which is a contagious disease of young and mature chickens characterized by low mortality, high morbidity as associated with chronic course, poor growth and productions (Peckham, 1984).

It is reasonable to assume that Campylobacter is the cause of a significant percentage of bacterial food-borne illness in humans and that poultry may be a vehicle responsible for a substantial portion of these illnesses (Sayed, 2000). It is imperative that sensitive methods for detection, enumeration, isolation and identification be used to assess the presence of $C$. jejuni and $C$. coli in poultry (Steinhauserova, 2001).

The present study was planned to investigate the prevalence of Campylobacter species in clinically diseased and apparent healthy, local bread chickens, to characterize biochemically the isolated Campylobacter strains and to clarify the frequency of recovery from different internal sites of studied chickens. Also to asses the pathogenisity, of one or more of the recovered organisms, by experimental chickens infection.

\section{MATERIALS and METHODS}

\section{Collection of samples:}

A total of 300 local breeds chickens (4 to 16 weeks old) which were collected from "El-Azzab project" at El-Fayoum Governorate, "Sedse project" at Beni Suef Governorate as well as from different private farms at El-Fayoum Governorate were employed. These were 
consisted of 250 clinically diseased sacrificed (emergency slaughtered) chickens and 50 apparent healthy cases.

Samples were collected from jejunum, caecum and gall bladder contents, liver tissues and heart blood. Samples from each case were separately collected using sterile mono-use disposable plastic glove, which was inverted after sampling and on which, sample information was written. All samples were transported to the laboratory in cold chamber container, within few hours for bacteriological procedures.

\section{Bacteriological examination:}

In the laboratory, a loop full from the homogenized suspension of liver tissues and the contents of gall bladder were directly streaked in duplicate onto plates of Bacto - Campylobacter agar, and Camp BAP medium (Blaser et al., 1984) and incubated anaerobically at $37 \mathrm{C}$ and $42^{\circ} \mathrm{C}$ for $48-72$ hours for direct isolation.

The pre-enrichment method was used for recovery of Campylobacter species from caecal and intestinal contents by dissolving one gram of fecal and gut fluid or mucous in one $\mathrm{ml}$ of sterile physiological saline. Centrifugation of the mixture at $1000 \mathrm{rpm}$ for 5 minutes was applied and few drops of the supernatant were inoculated into thioglycolate and tryptone - soy - broth and incubated anaerobically at $25{ }^{\circ} \mathrm{C}, 37^{\circ} \mathrm{C}$ and $42{ }^{\circ} \mathrm{C}$ for 48 hours. A loop full of each broth was streaked onto the surface of sheep blood agar with antibiotics and growth supplement. Also other few drops of supernatant were streaked directly on to the surface of Camp BAP medium and Bacto Campylobacter agar. All solid media were incubated microairophilically at 25,37 and $42 \mathrm{C}$ for $48-72$ hours for direct plating from intestinal samples.

The isolated colonies were identified morphologically and culturally and all Gram negative bacterial isolates showing the typical shape of Campylobacter (Hanninen, 1982) were carefully selected and the biochemical characterization tests were used according to Cruickshank et al. (1975); Collee et al. (1992); Koneman et al. (1996) and Tolba (2005).

\section{Experimental infection:}

One hundred and forty apparently healthy thirty days old local breed chickens received all vaccines against Newcastle, BD and IB viruses were divided into 7 equal groups (20 each). These chickens were reared on clean litters separately in a good ventilated conditions and fed on ration free from any antimicrobial feed additives. 
Chickens of the first group were infected orally with $0.5 \mathrm{ml}$ saline suspension of $1 \times 10^{9} \mathrm{cfu} / 1 \mathrm{ml}$ saline of $C$. jejuni for 2 successive days (Barson et al., 1994). The second group was I/M inoculated with $0.5 \mathrm{ml}$ of $1 \times 10^{9} \mathrm{cfu} / 1 \mathrm{ml}$ saline of $C$. jejuni. The third and fourth groups were also treated like group 1 and 2 respectively, but using C. coli:

The fifth and sixth groups were similarly treated like group 1 and 2 respectively, but were simultaneously infected with each of $C$. jejuni and $C$. coli. The seventh group was kept as a control non infected control group.

Clinical signs, morbidity, mortality and post mortem examination of freshly dead experimental chickens were recorded as well as reisolation of Campylobacter species from both dead and survived experimental chickens was employed.

\section{RESULTS}

The incidence of Campylobacter species recovered from diseased sacrificed (emergency slaughtered) and apparently healthy chicken samples are shown in Table (1). Out of the examined 88 isolated of campylobacter recovered from the diseased chickens, 45 were $C$. jejuni, 38 were $C$. coli and 5 were $C$. lardi with an incidence of $46.4 \%, 39.2 \%$ and $5.1 \%$ respectively (Table 1 ). From apparent healthy chickens the 9 recovered isolates consisted of $6 C$. jejuni and $3 C$. coli.

The total number of Campylobacter microorganism recovered from different sites of examined chickens is given in Table (2). The recovery rate was almost equal from the Jejunum (44.3\%) and caecum $(43.3 \%)$, while it was in a descending rate from the liver $(9.3 \%)$, gall bladder $(2.1 \%)$ and heart blood $(1.0 \%)$ as the number of Campylobacter species that were isolated from the jejunum, caecum, liver, gall bladder and heart blood was 43, 42, 9, 2, and one respectively. Eighty-five out of 97 Campylobacter isolates were recovered from the intestinal samples collected from all the examined chickens.

The frequency of Campylobacter species recovered from different sites of the examined diseased chickens is shown in Table (3). Campylobacter jejuni was mainly isolated from jejunum (29 isolates), followed by caecum (12 isolates), liver ( 3 isolates) and once from gall bladder contents. Campylobacter coli was mainly recovered from caecum (26 isolates), followed by jejunum ( 8 isolates), liver tissues (2 times), gall bladder and heart blood (1 isolate each). Campylobacter 
lari was recovered from jejunum (2 isolates) and liver tissues (3 isolates).

In apparent healthy chickens, Campylobacter jejuni was isolated from jejunum ( 3 isolates), followed by caecum ( 2 isolates) and liver tissues (1 isolate), while Campylobacter coli was recovered from caecum ( 2 isolates) followed by jejunum ( 1 isolate).

Results of experimental infection with Campylobacter jejuni showed that first mortalities was recorded 6 days post infection in orally infected group and 4 days post infection in group of chickens inoculated intramuscularly. Mortality rate was $20 \%$ in orally inoculated group of chickens and $30 \%$ in intramuscularly infected group (Table 4). Re isolation of the inoculated microorganism was recorded from the liver, caecum and jejunum from 3 (out of the 4 dead) orally infected chickens and from.5 (out of the 6 dead) intramuscularly inoculated ones. Rectal swabs that were collected from living chickens at the end of the experiment showed that $C$. jejuni was recovered from 3 living chickens of orally infected group and 2 from I.M. injected group.

Results of experimental infection with Campylobacter coli showed that first mortalities was recorded 5 days post infection in orally infected group and 3 days post infection in group of chickens inoculated intramuscularly. Mortality of $20.0 \%$ and $25.0 \%$ was recorded in oral route and intramuscular respectively (Table 4). Affected chickens showed, within 3-5 days, depression, fecal saturation of the vent plumage, and watery dropping, which persisted for 8-10 days. The principal change associated with $C$. coli infection comprises distention of the intestinal tract extending from duodenal loop to the bifurcation of the caeca. Re-isolation of the microorganism was recorded from the clotted heart blood of from the caeca of two out of the four dead orally infected group and from 3 out of 5 intramuscularly freshly dead chickens.

Results of concurrent experimental infection with Campylobacter jejuni and Campylobacter coli by oral infection, showed that 5 chickens $(25.0 \%)$ were died. Those consisted of 2 chickens died 5 days post infection, another 2 died 3 days later and 1 at the eleventh day post oral infection. The recorded lesions were mainly intestinal with clear or blood tinged mucus in duodenum, the caeca were distended and severe dehydration was noted in two dead chickens. Re-isolation of the two inoculated organisms was achieved from the intestinal contents of two dead chickens. Rectal swabs from living chickens gave positive results for $C$. jejuni only in two cases. 
In case of I.M. route of infection, death started two days post infection for 2 chickens and for other 3 chickens one day later, the last recorded mortality was in two chickens after 12 days from the beginning of experimental infection. Mortality rate amounted $35 \%$. The severity of clinically detectable changes was confines to depression and diarrhea. The presence of yellow/red mottling of the liver parenchyma was noted. Accumulation of mucus and watery fluid in duodenal loop was also noted. Haemorrhages in the intestinal tract were recorded in 3 chickens. Re-isolation of $C$. jejuni in combination with $C$. coli in a mixed from was achieved twice from heart blood and liver, while, $C$. jejuni was reisolated alone from other two chickens from the liver.

Table 1: Incidence of Campylobacter species recovered from the examined chickens.

\begin{tabular}{|c|c|c|c|c|c|c|c|}
\hline \multirow{2}{*}{ Health condition } & \multirow{2}{*}{$\begin{array}{c}\text { Total } \\
\text { No. of } \\
\text { isolates }\end{array}$} & \multicolumn{3}{|c|}{ Isolated Campylobacter microorganisms } \\
\cline { 3 - 8 } & & \multicolumn{2}{|c|}{ C.jejuni } & \multicolumn{2}{|c|}{ C.coli } & \multicolumn{2}{c|}{ C.lari } \\
\cline { 3 - 8 } & 88 & 45 & $46.4 \%$ & 38 & $39.2 \%$ & 5 & $5.1 \%$ \\
\hline Diseased: & 9 & 6 & $6.2 \%$ & 3 & $3.1 \%$ & 0 & $0.0 \%$ \\
\hline Apparent healthy & 97 & 51 & $52.6 \%$ & 41 & $42.3 \%$ & 5 & $5.1 \%$ \\
\hline Total & 97 & &
\end{tabular}

Table 2: Total number of Campylobacter species recovered from different sites of the examined chickens.

\begin{tabular}{|c|c|c|c|c|c|}
\hline \multirow{2}{*}{$\begin{array}{c}\text { Health } \\
\text { condition }\end{array}$} & \multicolumn{5}{|c|}{ Recovery site } \\
\cline { 2 - 6 } & Jejunum & Cecum & Liver & Gall bladder & Heart blood \\
\hline Diseased & 39 & 38 & 8 & 2 & 1 \\
\hline $\begin{array}{c}\text { Apparent } \\
\text { healthy }\end{array}$ & 4 & 4 & 1 & - & - \\
\hline Total (\%) & $\begin{array}{c}43 \\
(44.3 \%)\end{array}$ & $\begin{array}{c}42 \\
(43.3 \%)\end{array}$ & $\begin{array}{c}9 \\
(9.3 \%)\end{array}$ & $\begin{array}{c}2 \\
(2.1 \%)\end{array}$ & $\begin{array}{c}1 \\
(1.0 \%)\end{array}$ \\
\hline
\end{tabular}

Table 3: Frequency of Campylobacter species recovered from different sites of the examined diseased chickens.

\begin{tabular}{|c|c|c|c|c|c|c|}
\hline \multirow{2}{*}{ Recovery site } & \multicolumn{6}{|c|}{ Campylobacter species } \\
\cline { 2 - 7 } & \multicolumn{2}{|c|}{ C.jejuni } & \multicolumn{2}{c|}{ C.coli } & \multicolumn{2}{c|}{ C.lari } \\
\cline { 2 - 7 } & No. & $\%$ & No. & $\%$ & No. & $\%$ \\
\hline Jejunum & 29 & $33.0 \%$ & 8 & $9.1 \%$ & 2 & $2.3 \%$ \\
\hline Cecum & 12 & $13.6 \%$ & 26 & $29.6 \%$ & - & $0.0 \%$ \\
\hline Liver & 3 & $3.4 \%$ & 2 & $2.3 \%$ & 3 & $3.4 \%$ \\
\hline Gall bladder & 1 & $1.1 \%$ & 1 & $1.1 \%$ & - & $0.0 \%$ \\
\hline Heart blood & - & $0.0 \%$ & 1 & $1.1 \%$ & - & $0.0 \%$ \\
\hline Total & 45 & $51.1 \%$ & 38 & $43.2 \%$ & 5 & $5.7 \%$ \\
\hline
\end{tabular}


Table 4: Mortalities of experimentally infected chickens with the isolated Campylobacter strains.

\begin{tabular}{|c|c|c|c|c|c|c|}
\hline \multirow{3}{*}{$\begin{array}{c}\text { Microbe used / } \\
\text { infection } \\
\text { route }\end{array}$} & \multicolumn{6}{|c|}{ Campylobacter species used } \\
\hline & \multicolumn{2}{|c|}{ C.jejuni } & \multicolumn{2}{|c|}{ C.coli } & \multicolumn{2}{|c|}{ C.jejuni and C.coli } \\
\hline & Oral & I.M. & Oral & I.M. & Oral & I.M. \\
\hline Chickens & \multicolumn{6}{|c|}{ Number of experimental chickens used } \\
\hline & 20 & 20 & 20 & 20 & 20 & 20 \\
\hline \multicolumn{7}{|l|}{ Deaths: } \\
\hline 48 hours & & & & & & 2 \\
\hline 3 days & & & & 3 & & 3 \\
\hline 4 days & & 1 & & & & \\
\hline 5 days & & 2 & 2 & & 2 & \\
\hline 6 days & 1 & & 1 & 1 & & \\
\hline 7 days & & & & 1 & & \\
\hline 8 days & 1 & 2 & & & 2 & \\
\hline 9 days & & 1 & & & & \\
\hline 10 days & & & 1 & & & \\
\hline 11 days & 2 & & & & 1 & \\
\hline 12 days & & & & & & 2 \\
\hline Total deaths & 4 & 6 & 4 & 5 & 5 & 7 \\
\hline Death rate & $4 / 20$ & $6 / 20$ & $4 / 20$ & $5 / 20$ & $5 / 20$ & $7 / 20$ \\
\hline Percentage & $20 \%$ & $30 \%$ & $20 \%$ & $25 \%$ & $25 \%$ & $35 \%$ \\
\hline
\end{tabular}

\section{DISCUSSION}

Campylobacter species is an important agent that causes foodborne infection, particularly in food of poultry origin. Campylobacter jejuni and C. coli has become recognized as a common etiological agent in human diarrheas. This fact had led to announce (on December, 2007) that "This has been the year of eating dangerously" (Lundy, 2007). He declared that "Consumer Reports" got things rolling in the Cincinnati Enquirer reported that 83 percent of all raw chickens harbor Campylobacter or Salmonella, leading causes of food- borne disease.

Campylobacter microorganisms are widely spread in boiler farms as reported by both wieliczko (1995A) and Jacobs-Reitsma et al. (1994) and the chickens can be infected by Campylobacter microorganisms at 4-6 weeks of age. Therefore, the efficient control of the transmission routes in chicken farms is of outmost importance to prevent it from spreading (Fonseca et al., 2006).

It is well known that the recovery of Campylobacters is greatly influenced by oxygen content of the gaseous atmosphere in contact with 
enrichment and isolation media. Campylobacter jejuni and C. coli are sensitive to air, surviving only 1 to 2 days in solid media, 2 to 4 days in liquid media, and 10 to 20 days in semisolid media at room temperature and survival can be enhanced by holding cultures at $4^{\circ} \mathrm{C}$ and by reducing oxygen tension. (Park et al., 1984). These fact acts the main obstacles that encountered in the laboratories that working in the isolation and identification of Campylobacter microorganisms.

In this study, 97 cases were found to be positive for campylobacter with an incidence of $32.3 \%$. Those cases consisted of 88 isolates were recovered from 250 clinically diseased sacrificed (emergency slaughtered) chickens and 9 isolates from 50 apparent healthy ones.

Out of the examined 88 isolated of Campylobacter recovered from the diseased chickens, 45 were $C$. jejuni, 38 were $C$. coli and 5 were $C$. lardi with an incidence of $46.4 \%, 39.2 \%$ and $5.1 \%$ respectively (Table, 1). From apparent healthy chickens the 9 recovered isolates consisted of $6 C$. jejuni and 3 C. coli.

The total number of Campylobacter microorganisms recovered from different sites of the examined chickens is given in Table (2). The recovery rate was almost equal from the Jejunum (44.3\%) and caecum $(43.3 \%)$, while it was in a descending rate from the liver $(9.3 \%)$, gall bladder $(2.1 \%)$ and heart blood $(1.0 \%)$ as the number of Campylobacter species that were isolated from the jejunum, caecum, liver, gall bladder and heart blood was 43,42, 9, 2, and one respectively.

The frequency of Campylobacter species recovered from different sites of examined diseased chickens is shown in Table (3). Campylobacter jejuni was mainly isolated from jejunum (29 isolates), followed by caecum (12 isolates), liver (3 isolates) and once from gall bladder contents. Campylobacter coli was mainly recovered from caecum (26 isolates), followed by jejunum ( 8 isolates), liver tissues (2 times), gall bladder and heart blood (1 isolate each). Campylobacter lari was recovered from jejunum (2 isolates) and liver tissues (3 isolates).

In apparent healthy chickens, Campylobacter jejuni was isolated from jejunum (3 isolates), followed by caecum (2 isolates) and liver tissues (1 isolate), while Campylobacter coli was recovered from caecum ( 2 isolates) followed by jejunum ( 1 isolate).

Our results agreed with that of different authors, as the higher incidence of $C$. jejuni was explained as because chicks are coprophagic by nature, and $C$. jejuni readily colonizes in the chick, a rapid 
transmission through an entire flock could be expected (Pokamunski et al., 1986). Jacobs-Reitsma et al. (1994) recorded that the flocks became colonized with Campylobacter at about 3-4 weeks of age with isolation percentage of $100 \%$ and stayed colonized up to slaughter. Wieliczko (1995B) failed to isolate Campylobacter from 1-7 day-old chicks and the rate of isolation was $30.8,76.5,72.5$ and $66.5 \%$ for broilers aged 14, 21, 21, 35 and 47 days respectively. The most prevalent strains were C. jejuni (51.4\%), C. coli $(21.9 \%)$ and Campylobacter did not colonized the intestinal contents in broilers before days 13-14 after hatching

The frequency of Campylobacter species recovered from different sites of examined diseased chickens is shown in Table (3). Campylobacter jejuni was mainly isolated from jejunum (29 isolates), followed by caecum (12 isolates), liver (3 isolates) and once from gall bladder contents. Campylobacter coli was mainly recovered from caecum (26 isolates), followed by jejunum ( 8 isolates), liver tissues (2 times), gall bladder and heart blood (1 isolate each). Campylobacter lari was recovered from jejunum ( 2 isolates) and liver tissues (3 isolates).

In apparent healthy chickens, Campylobacter jejuni was isolated from jejunum (3 isolates), followed by caecum (2 isolates) and liver tissues ( 1 isolate), while Campylobacter coli was recovered from caecum ( 2 isolates) followed by jejunum (1 isolate).

The presented results showed that it was found that jejunal and caecal contents followed by liver tissue, bile and finally heart blood were the sites of recovery in a descending manner. Also, C. lari was recovered from liver and jejunum only. Eighty-five out of 97 Campylobacters isolates were recovered from the intestinal samples collected from the examined chickens. This result almost agreed with Vaema et al. (2000) who succeeded to isolate $C$. jejuni from 25 cloacal samples of live poultry and from 15 intestinal swabs from dead birds. They added that $48 \%$ of cloacal samples and $33.4 \%$ of intestinal swabs were confirmed to contain C. jejuni .Recently,Burgess et al. (2005) concluded that, $C$. jejuni and $C$. coli accounted for $59 \%$ and $24 \%$ of the raw chickens contaminating microorganisms. Mean while, Stern and Robach (1995) stated that caecal droppings were the most suitable non destructive samples for assessing Campylobacter species, while on the other hand, Oyarzabal et al. (1995) succeeded to isolate Campylobacter species only from 18 out of 91 avian intestinal swabs. Generally, the mechanisms by which $C$. jejuni is introduced into the poultry house 
remains unclear, although a variety of potential sources have been implicated, including water (Pearson et al. (1993), insects (Rosef and Kapperud, 1983), farm personal (Kazwala et al., 1990) and rodents (Stern, 1992).

In this work an experimental design was planned to study the pathogenisity of $C$. jejuni and $C$. coli, in a single or mixed form, in the production of disease condition in chickens. Inoculation of $C$. jejuni in single form intramuscularly produced $30.0 \%$ mortalities compared with $20.0 \%$ mortalities when given orally. The mostly affected organs were the liver, caeca and jejunum with reisolation of the inoculated organism from the liver, caeca and jejunum.

On the other hand, $C$. coli produced $25.0 \%$ and $20.0 \%$ mortalities when inoculated intramuscularly and orally respectively. The principal changes were associated with C.coli infection was in the form of distension of the intestinal tract.

Intramuscular inoculation of $C$. jejuni and $C$. coli in a mixed form produced $35.0 \%$ mortality rate with severely detectable pathological changes in the liver, accumulation of mucus and watery fluid in duodenal loop and haemorrhages in the intestinal tract. The mortality rate lowered to be $25.0 \%$ accompanied with severe dehydration and blood tinged duodenal mucosa when the two organisms were inoculated orally.

Our results agreed with different reports, Ruiz-palacois et al. (1981) who performed experimental infection with $9 \times 10^{7} \mathrm{CFU}$ of C. jejuni orally and the recorded mortality was $32 \%$. Clarck and Bueschens (1988) mentioned that the pathological lesion of chicks infected with $C$. jejuni included distended intestinal tract and abnormal gross liver pathology. Berndtson et al. (1996) concluded that the colonization of poultry by $C$. jejuni induces a specific secretory $\operatorname{IgA}$ response which appears to play an important role in colonization reduction. On the other hand, Young et al. (1999) concluded that different $C$. jejuni isolates vary in both their ability to colonize the caeca and their ability to invade the liver.

For conclusion, this study provided that Campylobacter species are widely spread in local breed broiler farms with a mean incidence of $32.3 \%$ which ranged from $35.2 \%$ in diseased and $18 \%$ in apparent healthy chickens. These microorganisms mainly colonize the jejunum (mainly $C$. jejuni) and caecum (mainly $C$. coli) and also, can colonize the liver tissues. Regarding the biochemical identification of Campylobacter species, there were some differences within the same 
species in its biochemical activities. Experimental infection with more than one type of Campylobacter species increased the mortality rates and severity of post mortem findings than those obtained when each organism was inoculated singly

\section{REFERENCE}

Barson, E.J.; Oeterson, L.R. and Finegold, S.M. (1994): Baily and Scoht's Diagnostic Microbiology, $9^{\text {th }}$ Ed. Mosby, London, M.K.

Berndtson, E.; Donielesson, M.L. and Engvall, A. (1996): Campylobacter incidence on a chickens farm and the spread of Campylobacter during the slaughter process. Int. J. Food. Microbiol. 32: 35-47.

Blaser, M.J.; Laforce, F.M.; Wilson, N.A. and Wang, W.L. (1984): Reservoirs for human Campylobacterioses. J. Infect. Dis., 141: 665-669.

Bolton, F.J.; Wareing, D.R.A.; Skirrow, M.B. and Hutchinson, D.N. (1992): Identification and Biotyping of Campylobacters. In Identification Methods in Applied and Environmental Microbiology ed. Board, R.G.; Jones, D. and Skinner, F.A. PP. 151-161- Oxford: Black well Scientific Publication.

Burgress, F.; LiHle, C.L.; Allen, G.; Williomson, K. and Mitchelli, R.T (2005): Prevalence of Campylobacter, Salmonella, and Escherichia coli on the external packaging of raw meat. J. Food. Prot., b8 (3): 469-475.

Clarck, A.G. and Bueschens, D.H. (1988): Horizontal spread of human and poultry-derived strains of Campylobacter jejuni among broiler chicks held in incubators and shipping boxes. J. Food. Prot., 51(6): 438-441.

Collee, J.G.; Duguid, J.P.; Fraser, A.G. and Marmion, B.P. (1992): Mackie and McCartney Y Practical Medical Microbiology. $13^{\text {th }}$ Ed., The English Language Book Society and Churchill Living Stone, Edinburgh and New York.

Cruickshank, R.; Duguid, J.P.; Marmion, B.P. and Swain, R.H.A. (1975): Medical Microbiology $12^{\text {th }}$ Ed. (Vol. 2), Churchill Living Stone Limited, Edenburgh, London and New York.

Fonseca, B.B.I.; Soncini, R.A.; Vieira, F.L.; Siqueira, M.S.; Guimarães, A.R.; Beletti, M.E. and Rossi, D.A. (2006): Campylobacter sp in organs and meconium of day-old broiler chicks derived from 
naturally infected breeder hens. Rev. Bras. Cienc. Avic., 8(4) Campinas Oct./Dec. 2006.

Hanninen, M.L. (1982): Characterization of Campylobacter jejuni /coli isolated from different sources. Acta Veterinaria Scandinovica., 23 (1): 88-98.

Jacobs-Reitsma, W.F.; Bolder, N.M. and Mulder, R.W.A.W. (1994): cecal carriage of Campylobacter and Salmonella in Dutch broiler flocks at Slaughter: a one year study. Poult. Sci., 73 (8): 1260-1266.

Kazwala, R.R.; Collins, J.D.; Hannan, J.; Crinion, R.A.P. and oMahony, H. (1990): Factors responsible for the spread of Campylobacter jejuni infection in commercial poultry production. Vet. Record., 126.

Koneman, E.W.; Allen, S.D.; Jand, W.M.; Schrechen-Berrjer, P.C. and Winn, W.J.R. (1996): Colour Atlas and Text book of Diagnostic Microbiology $5^{\text {th }}$ Ed., J.B.L. ppinco HC., Philadelphia, U.S.A.

Lundy, C. (2007): Campylobacter jejuni, the BAD BUG Book Campylobacter Blog, TAGS Campylobacter Resources http://www.campylobacterblog.com/articles/campylobacterresources/

Oyarzable, O.A.; Conner, D.E. and Hoerr, F.J. (1995): Incidence of Campylobacter in the intestine of avian species in Alabama. Av. Dis., 39 (1): 147-156.

Park, C.E.R.M.; Smibert, M.J.; Blaser, C.; Vanderzant, and N.J. Stern. (1984): Compendium of Methods for the Microbiological Examination of Foods., M. T. Speck, ed. Am. publi. Health. Assoc., Washington, DC., 366-404.

Pearson, A.D.; Green Wood, M.; Healing, T.D.; Rollins, D.; Shabamat, M.; Donaldson, J. and Colwell, R.R. (1993): Colonization of broiler chickens by water borne Campylobacter jejuni. Appl. Environmental Microbiol., 59: 987-996.

Peckham, M.C. (1984): Avian vibrio infection in M.S. Hofstad, H.J. Barnes, B.W. yover, Jr. (eds): disease of poultry, $8^{\text {th }}$ Ed., PP. 221-231. Iowa State Univ. Press, Ames.

Pokamunski, S.; Kass, E.; Borochovich, B.; Marantz, and M. Rogol, (1986): Incidence of Campylobacter species in broiler flocks monitored from hatching to slaughter. Avian Pathol., 15: 83-92 
Rosef, O. and Kapperud, G. (1983): House flies as possible vectors of Campylobacter fetus subspecies jejuni. Appl. Environment. Microbiol., 45: 381-383.

Ruiz-Palacois, G.M.; Escamilia, E. and Torres, N. (1981): Experimental Campylobacter diarrhoea in chickens. Infect. immunol., 34 (1): 250-255.

Sayed, A.M. (2000): Campylobacter infection in broiler chickens in Assiut J. Ass. Vet. Medic., 42 (84): 213-221.

Simon, M. Shane (1992): The significance of Campylobacter jejuni infection in poultry. Avian Pathol., 12: 189-213.

Simmons, N.A. and Gibbs, F.J. (1979): Campylobacter species in oven ready poultry. J. Infect., I (2): 159-162.

Steinhauserova, I.; Ceskova, J.; Fujtikova, K. and Obravska, I. (2001): Identification of thermophilc Campylobacter species by phenotypic and molecular methods. J. Appl. Microbiol., 90 (3): 470-475.

Stern, N.J. (1992): Reservoirs for Campylobacter jejuni and approaches for intervevtintion in Poultry in Campylobacter jejuni: Current status and future trends (Eds Nachamkin, I., Blaser, M.J., Tompkins, L.S.), American Society for Microbiology, Washington, DC, PP. 49-60.

Stern, N.J. and Robach, M.C. (1995): Non destruction sampling of live broilers for Campylobacter, J. Appl. Poult., 4 (2): 182-85.

Tolba, Nagla, F.K. (2005): A study on Campylobacter species in chickens in El-Fayoum governorate. A Thesis M.V.Sc. presented to Fac. Vet. Med., Beni-Suef Branch, Cairo Univ.

Varma, K.S.; Jagadeesh, N.; MuKhopadhyay, H.K. and Dorairajan, N. (2000): Incidence of Campylobacter jejuni in poultry and their carcasses Journal of foods science.

Wieliczko, A. (1995-A): The role of Campylobacter in poultry pathology. Part I. Epidemiolobacter infections in poultry. Medycynaryina., 51(3): 150-152.

Wieliczko, A. (1995-b): Role of Campylobacter in poultry pathology. Part III. influence of feed additives on the colonization of the digestive tract with $C$. jejuni Medycyna. Weterynaryina, 51(11): 693-696.

Young, C.R.; Ziprin, R.L.; Tlume, M.E. and Stanker, L.H. (1999): Dose response and organ invasion of day-of-hatch leghorn chicks by different isolates of Campylobacter jejuni. Av. Dis., 43 (4): 763-767. 
Assiut Vet. Med. J. Vol. 54 No. 119 October 2008 